\title{
The Effect of Metalanguage on Grammar Noticing of the Iranian EFL Learners
}

\author{
Anita Roshan ${ }^{1} \&$ Ali Elhami ${ }^{1}$ \\ ${ }^{1}$ M.A. in Applied linguistics, Tehran, Iran \\ Correspondence: Anita Roshan, M.A. in Applied linguistics, Tehran, Iran. E-mail: a.roshan.anita@gmail.com
}

Received: February 28, 2016 Accepted: April 13, 2016 Online Published: May 25, 2016

doi:10.5539/ijel.v6n3p194 URL: http://dx.doi.org/10.5539/ijel.v6n3p194

\begin{abstract}
Metalanguage did not receive a lot of attention in communicative language teaching (CLT) but has remained an untouched area in second language studies. This research wanted to examine the effect of teachers' metalanguage on learners' noticing of grammatical points. This research was conducted at two proficiency levels of elementary and intermediate. In each level of elementary and intermediate, two groups were chosen, an experimental and a control group. In the experimental group, the teachers used metalanguage to teach grammar points. However, in control group the teachers used examples to teach grammar points. A noticing task test was administered to the two groups to collect data. The result indicated that the metalanguage had impacted the learners' noticing, of grammatical points.
\end{abstract}

Keywords: metalanguage, noticing, Consciousness Raising (CR), metalinguistic terminology

\section{Introduction}

\subsection{Background}

Metalinguistic terminology is a technical term that is used to name grammatical items. For example, present continuous is a label or name for a grammatical point that called grammatical terminology or metalinguistic terminology. So metalinguistic terminology may help teachers to talk about language, however Berry (2014) claims that "it is quite possible to talk about language without any terminology at all" (p. 25).

There are many advantages of using metalanguage in L2 classrooms. Hu (2010) briefly mentions five of them that are the most important advantages:

First and foremost, it develops learners' knowledge of forms and functions. "Knowledge and use of metalanguage have the potential to facilitate the development of an L2 learner's metalinguistic awareness-that is, (Carter, 2003, cited in $\mathrm{Hu}, 2010$ ) an enhanced consciousness of and sensitivity to the forms and functions of language" (p. 64). So by focusing on the language, learners understand the grammar points with conscious attention, and they can develop the skill of verbalizing and analyzing the language.

The second advantage of metalanguage is the use of similarities between L1 and L2. Hu also states that "the use of metalanguage in the L2 classroom is a useful way to measure the wealth of metalinguistic awareness that learners have developed in the process of acquiring L1 literacy" (p. 65). For example learners that have learned different labels such as noun, verb, adjective, adverb, so on, in their native language can make sense between L1 and L2 as they are learning the second language.

Third, $\mathrm{Hu}$ (2010) claims that when the teacher and students avoid using metalanguage, there will be some difficulties and disadvantages in grammar instruction. Even in English classes that the method of teaching is CLT, they sometimes desire to talk about language explicitly (p. 65). He also believes that "such a discussion can be used either to raise learners' consciousness about the target structures or to provide an opportunity for them to confirm or modify the rules they have internalized as a result of their own hypothesis formation and testing. However, it is difficult to see how an explicit discussion of complex structures, such as unreal conditionals and relative clauses, can be conducted without recourse to metalanguage" (p. 65).

$\mathrm{Hu}$ (2010) points out that the next advantage of using metalanguage "concerns the explanatory precision with which linguistic generalization can be made and the efficient delimitation of the contexts to which the generalization applies. Metalanguage that is appropriately used can preempt both under- and over-generalization 
of the rules in question.” (p. 66). In the other words, by using different examples for grammar rules, learners may make wrong generalizations.

Another advantage is the use of metalanguage for comparing and contrasting the new grammatical rule with that the one the learners have already learned. $\mathrm{Hu}$ (2010) points out that "metalanguage and concepts of L2 structural properties already learned can be exploited as points of reference or anchoring sites for the assimilation of new knowledge" (p. 66).

Noticing has an important role in second language learning, and most of the researchers are interested in investigating it. Schmidt (1990, cited in Brown) refers to it as noticing hypothesis, and he believes that without focal attention or noticing input cannot convert to intake (pp. 292-293). Burns \& Richards (2012) point out that:

Noticing refers to process of the learner picking out specific features of the target language input which she or he hears or reads, and paying conscious attention to them so that they can be fed into the learning process. This involves making connections between grammatical features noticed and their associated meanings, functions and contexts of use. The importance of noticing is associated in particular with work of Schmidt (1990), who concluded that noticing was the process by which input was converted into intake. (p. 260)

In grammar instruction when the teacher uses metalanguage, in fact the purpose is to attract the students' attention to grammar points. The teacher tries to raise their metalanguage awareness and noticing in order to facilitate learning. Teachers can use metalanguage to enhance grammar, reading and writing. However, in this study the focus is the use of metalanguage in teaching grammar.

\subsection{Significance of the Study}

The significance of this research can be sought from two perspectives: theoretical and practical. From the theoretical point of view, it can help researchers to establish a clear relationship between teachers' metalanguage and leaners' noticing of grammar points. From the practical point of view, it might contribute to increasing the teachers' awareness of how metalanguage works in EFL classes.

\subsection{Research Question}

Does metalanguage have any impact on the noticing of the Iranian EFL learners of different levels?

\subsection{Research Hypothesis}

The research hypothesis of the present study also can be stated as follows:

Metalanguage does not make a statistically significant difference in noticing grammatical points at different levels.

\section{Literature Review}

\subsection{Consciousness Raising (CR)}

Consciousness raising (CR) is an approach for teaching grammar that helps learners to improve their explicit knowledge of grammar. Ellis (2002) points out that "this is not the same as metalinguistic knowledge. It is perfectly possible to develop an explicit understanding of how a grammatical structure works without learning much in the way of grammatical terminology. Grammar can be explained, and, therefore, understand in everyday language. It may be, however, that access to some metalanguage will facilitate the development of explicit knowledge" (p. 196). According to Rutherford \& Sharwood-Smith (1985) CR is "the deliberate attempt to draw the learner's attention specifically to the formal properties of the target language" (cited in Cullen, 2012, p. 261).

Some researchers believe that CR facilitates learning, however some others claim that language learning is not a conscious process. Seliger (1981) "has claimed that obviously, it is at the unconscious level that language learning takes place" (cited in Schmidt, 1990, p. 129). Although Schmidt (1990) points out that "there are many who believe that conscious understanding of the target language system is necessary if learners are to produce correct forms and use them appropriately. In this view, errors are the result of not knowing the rules of the target language, forgetting them, or not paying attention". There are three senses of consciousness: consciousness as awareness, consciousness as intention and consciousness as knowledge (Schmidt, 1990, p. 133).

\subsection{Noticing}

Schmidt (1990) mentions there levels of awareness such as perception, noticing (focal awareness) and understanding. Oakley (1985) and Baars (1986) believe that "all perception implies mental organization and the ability to create internal representations of external events" (cited in Schmidt, 1990, p. 132). In noticing level of awareness Schmidt (1990) cites Bowes (1984)'s claim that points out "the crucial distinction between information that is perceived and information that is noticed" (p. 132). 
Furthermore, he believes that when we are reading something, we generally pay attention or notice the content of the text. Although there are other things such as the style of the text or writer, noises around us and the sound of music, however we can choose which of these we want to notice and pay attention.

Generally in a conscious experience, it is difficult to describe something that we noticed. For example Schmidt (1990) points out that we may find out two wins differences and notice them but we are not able to describe them, Or notice a person with a regional accent but we cannot explain it phonetically. Therefore he believes that "when problems of memory and metalanguage can be avoided, verbal reports can be used to both verify and falsify claims concerning the role of noticing in cognition". (p. 132)

The last level of awareness is understanding. When we notice something and think about it we can analyze and compare it with something else that we noticed in another occasion. These mental activities are related to consciousness and problem solving is its example. (Schmidt, 1990, p. 132)

According to Schmidt (1994) "noticing refers to the registration [detection] of the occurrence of a stimulus event in conscious awareness and subsequent storage in long term memory" (p. 179, cited in Al-Hejin, 2005, p. 3). Al-Hejin (2005) represents in his study the Schmidt's definition of noticing "noticing= detection + awareness", and because detection is a part of awareness, he simplifies it to "noticing=awareness" (p. 4). Furthermore, Al-Hejin (2005) claims that "reviewing the psychological literature on consciousness has led Schmidt to propose the Noticing Hypothesis" (p. 14).

There are different studies about the crucial role of noticing in language learning. Truscott (1998) argues that Schmidt's noticing hypothesis is "a claim about how input becomes intake - that part of the input that is used for acquisition. It claims that conscious awareness (noticing) of grammar plays an important role in the process" (p. 103).

Noticing Hypothesis of Schmidt has two versions, strong and weak. In strong version "noticing is a necessary condition for learning", however in weak version "noticing is helpful but might not be necessary" (Schmidt, 1990; 1993a; 1994; 1995b, cited in Truscott, 1998, p. 103). In addition, Schmidt (1995) distinguishes between noticing and understanding, "which Schmidt defines as "recognition of a general principle, rule or pattern" (p. 29, cited in Al-Hejin, p. 4). Furthermore, Schmidt (2001) points out that "understanding represents a deeper level of awareness than noticing which is limited to "elements of the surface structure of utterances in the input" rather than underlying rules" (p. 5, cited in Al-Hejin, p. 4).

Because of the importance of noticing in language learning and acquisition, recently there are lots of studies about it. Schmidt \& Frota (1986, cited in Thornbury, 1997) suggest that two kinds of noticing are necessary condition for acquisition:

1) Learners must attend to linguistic features of the input that they are exposed to, without which input cannot become "intake".

2) Learners must "notice the gap", i.e., make comparisons between the current state of their developing linguistic system, as realized in their output, and the target language system, available as input.

For the purpose of raising the students' attention to the language form, the teacher needs to use some classroom activities and techniques such as "input enhancement" and "input flooding". Decarrico \& Larsen-Freeman (2002) point out that input enhancement is a technique that is used by the teacher to attract the students' attention to a special feature such as a new grammar point or vocabulary. In this case the students are given a text with bold fonts in some parts or a gap-filling in a listening text. Moreover, in input flooding, the teacher bombards students with a lot of target form examples. (cited in Cullen, 2012, p. 260)

In addition, Swain $(1995,2000)$ and Thornbury (1997) claim that noticing the gap (another aspect of noticing) is "where learners notice gaps that exist between their current state of knowledge (their interlanguage) and the target language system" (cited in Cullen, 2012, p. 260).

\section{Method}

\subsection{Participants}

The participants of this study were selected from Tehran Institute of Technology. The participants of this research were selected by the Oxford Placement Test administered to learners in four classes already organized by the institute officials.

The experimental group and the control group of the elementary level each included twelve learners, that came to 24 participants altogether. On the other hand, the experimental and the control group of the intermediate level was each composed of thirteen participants, that came to 26 participants. 


\subsection{Instruments}

The following instruments were used in order to collect the required data for this research:

(a). Oxford Quick Placement Test: Although the learners are required to take the institute placement test, the Oxford Placement Test was administered to further guarantee that the learners were homogenously selected. The test include two part. The first part is composed of 40 items which all the students in the two groups, that is the elementary and intermediate groups, were asked to answer. However, only the learners in the intermediate level were required to answer the next twenty questions which were from 41 to 60 .

(b). Voice Recording: The teacher's voice was recorded not as a tool to collect data, but to make sure that he used metalanguage.

(c). Noticing Task: the noticing task in the current study includes 10 sentences about the grammar point. Eight of the items are incorrect and two of them are correct, and the students were asked to identify the incorrect sentences and correct them.

\subsection{Procedure}

The first step was to administer the Oxford Quick Placement test in order to guarantee the homogeneity of the learners with regard to their proficiency levels. Two levels of elementary and intermediate were selected for the present research. In each level, there were one control and one experimental group. The teacher in elementary level to taught "articles" (a/an vs the) using only metalanguage in the experimental group and only examples in the control group. All the students in this level had already learned the articles "a" and "an"; however, they were going to learn the article "the" and distinguish it from "a/an".

In the intermediate group, the teacher was requested to teach "so and such" using only metalanguage in the experimental group and only examples in the control group.

Next, a task of 10 items was used in each class to tap the students' noticing of the grammar point.

\subsection{Data Analysis}

A Two-way multivariate ANOVA (2-way MANOVA) was run to answer the research question.

\section{Result}

The research question of this study aimed at investigating whether metalanguage has any impact on noticing of Iranian EFL learners of different levels. We used independent samples $t$-test in order to answer this research question. The descriptive statistics of the treatment and control noticing scores are set forth in Table 1 before discussing the results of independent samples $t$-test. As Table 1 displays, in elementary level, mean of noticing for treatment group $(\bar{x}=5.92, S D=2.39)$ is not very different from control group $(\bar{x}=5.08, S D=2.19)$ though mean is a bit larger in value in favor of treatment group. In contrast, Table 3 shows that, in intermediate level, mean of noticing for treatment group $(\bar{x}=7.08, S D=2.39)$ is evidently greater than control group $(\bar{x}=5.00$, $S D=2.30)$.

Table 1. Descriptive statistics for noticing scores (Elementary \& Intermediate)

\begin{tabular}{lllllll}
\hline Level & Group & $N$ & Mean & $S D$ & Skewness & Kurtosis \\
\hline \multirow{2}{*}{ Elementary } & Treatment & 12 & 5.92 & 2.392 & -.313 & -.164 \\
& Control & 12 & 5.08 & 2.193 & .184 & -.541 \\
\multirow{2}{*}{ Intermediate } & Treatment & 13 & 7.08 & 2.397 & -1.128 & 1.742 \\
& Control & 13 & 5.00 & 2.309 & .384 & -.941 \\
\hline
\end{tabular}

Table 2 below represents the results of independent samples $t$-test that was used to compare the treatment and control groups' noticing scores in elementary and intermediate levels. Based on Table 2, the assumption of equality of variances in not violated (Sig. > .05). 
Table 2. Independent samples T-test for noticing scores (Elementary \& Intermediate)

\begin{tabular}{|c|c|c|c|c|c|c|c|}
\hline \multirow[b]{2}{*}{ Level } & \multicolumn{3}{|l|}{ Levene's Test for Variances } & \multicolumn{3}{|c|}{$T$-test for Means } & \multirow[b]{2}{*}{ Mean Diff. } \\
\hline & Factor & $F$ & Sig. & & $d f$ & Sig. (2-tailed) & \\
\hline Elementary & Equal variances assumed & .002 & .961 & .890 & 22 & .383 & .833 \\
\hline Intermediate & Equal variances assumed & .022 & .883 & 2.250 & 24 & .034 & 2.077 \\
\hline
\end{tabular}

The results of independent $t$-test, as appeared in Table 2, indicates that there is no statistically significant difference in noticing scores for treatment $(\bar{x}=5.92)$ and control $(\bar{x}=5.08)$ groups in elementary level, $(t(22)$ $=.89, p=.38, p>.05$, in which the $t$-observed is lower than the $t$-critical (2.02). Thus, declare that metalanguage does not improve noticing of Iranian elementary EFL learners.

On the other hand, independent samples $t$-test (Table 2) detected a statistically significant difference in noticing scores for treatment $(\bar{x}=7.08)$ and control $(\bar{x}=5.00)$ groups in intermediate level, $t(24)=2.25, p<.05$, in which the $t$-observed is above the $t$ critical (2.02). Accordingly, we can claim that metalanguage enhances noticing of Iranian intermediate EFL learners.

We made a Bar Graph to show the results (Figure 1). Figure 1 illustrates that, in elementary level, the students in the treatment and control groups have not acted very far from each other regarding noticing. But in intermediate level, the students in the treatment group have outperformed those in the control group on the subject of noticing.

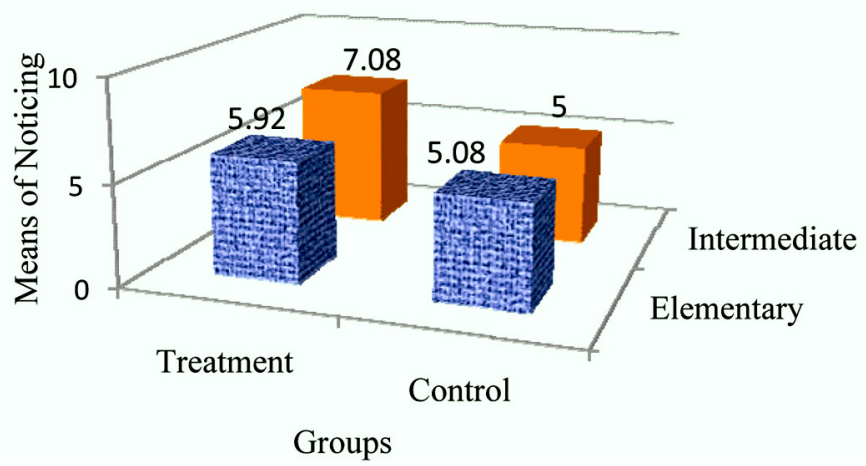

Figure 1. Two groups' noticing means in elementary and intermediate levels

\section{Discussion}

As shown in the previous section, the hypothesis of the current research has been rejected. However, the noticing mean of the elementary level is not much different from the intermediate level.

Not a lot of studies have been done on the relationship between teachers' metalanguage and learner's noticing of grammar points. However, a comparison and a contrast are made between the findings of this study and those of others.

The findings of this research are in contrast with those of the research done by Arghamiri \& Sadighi (2013) claim that "as the students' proficiency level increases, their understanding of the knowledge about language also increases". In their study, they investigated learners' metalanguage, but in the current research teacher's metalanguage was the focus of research.

The findings of this study are in line with Roehr (2008) and Elder (2009) who found positive correlations between metalinguistic knowledge and proficiency test results in more advanced learners, and found significant correlations between students' proficiency test scores and metalinguistic knowledge" (p. 8). In the present study, all the learners in the intermediate level outperformed those in the elementary level.

Furthermore, the results of the present research correspond to those found by Tokunaga who found that there was a strong relationship between proficiency levels and metalanguage, something which was demonstrated in the current study.

The present research does not correspond to the finding of research by Hu \& Ellis (1998). Again here they 
conducted their study on learner' metalanguage. However, their study proved that the use of metalanguage affected the test takers' performance on proficiency tests.

Overall, all the studies done so far put the stamp of approval on the use of metalanguage as an effective tool in second language development. But most studies have concentrated on learner's use of metalanguage rather than the teacher's.

\section{Conclusion}

The aim of this study was to find a relationship between teachers' use of metalanguage and learners' noticing of grammatical points across proficiency levels.

Regarding the hypothesis, MANOVA identified significant differences between the target and control groups on noticing $(F(1,46)=4.88, p=.03, p<.05$, Partial $\eta 2=.09$ representing a small effect size); as a result, the null hypothesis of the current study reading as "Metalanguage does not have any impact on noticing of the Iranian EFL learners of different levels" was rejected.

\section{Limitations of the Study}

Doing the present study, the researcher could not control some factors. First of all, although she briefed each teacher on using metalanguage in the class, but the way he used it was not under the researcher's control. For instance, a teacher may or may not have used examples to explain a grammar point. Another limitation was the teacher's experience and expertise in teaching English. A teacher might have two or more years' experience teaching English. In fact, this can affect how a teacher can effectively use metalanguage. Finally, to have adequate number of subjects, the researcher had to include both male and female EFL learners.

\section{References}

Al-Hejin, B. (2005). Attention and awareness: evidence from cognitive and second language acquisition research. Teachers College, Columbia. University working papers in TESOL \& Applied Linguistics, 4(1), 1-18. Retrieved from http://tesol-dev.journals.cdrs.columbia.edu/

Arghamiri, A., \& Sadighi, F. (2013). The Impact of Metalinguistic Knowledge and Proficiency Level on Pragmatic Competence of Iranian EFL Learners. International Journal of Language Learning and Applied Linguistics World (IJLLALW), 4(1), 181-192. Retrieved from http://www.ijllalw.org/finalversion4114.pdf

Bachman, L. F. (2005). Statistical analysis for language assessment (2nd ed.). Cambridge: Cambridge University Press.

Berry, R. (2014). Investigating language awareness: the role of terminology. Second Language Learning and Teaching (pp. 21-33). Berlin: Springer. http://dx.doi.org/10.1007/978-3-319-00461-7_2

Burns, A., \& Richards, J. C. (2012). Pedagogy and practice in second language teaching. Cambridge: Cambridge University Press.

Field, A. (2009). Discovering statistics using SPSS (3rd ed.). London: SAGE.

$\mathrm{Hu}$, G. (2010). Revisiting the role of metalanguage in L2 teaching and learning. EA Journal, 26(1), 61-66. http://dx.doi.org/10.1017/cbo9781139524780.003

Schmidt, R. (1990). The Role of Consciousness in Second Language Learning. Applied linguistics, 11(2), 129-132. Oxford: Oxford university press. http://dx.doi.org/10.1093/applin/11.2.129

Schmidt, R. (2001). Attention. Cambridge University Press. http://dx.doi.org/10.1017/cbo9781139524780.003

Thornbury, S. (1997). Reformulation and reconstruction: tasks that promote "noticing". ELT Journal, 51, 326. http://dx.doi.org/10.1093/elt/51.4.326

Truscott, J. (1998). Noticing in second language acquisition: a critical review. Second language research, 14(2), 103. http://dx.doi.org/10.1191/026765898674803209

\section{Copyrights}

Copyright for this article is retained by the author(s), with first publication rights granted to the journal.

This is an open-access article distributed under the terms and conditions of the Creative Commons Attribution license (http://creativecommons.org/licenses/by/3.0/). 